\title{
Ergosterol biosynthesis and drug development for Chagas disease
}

\author{
Julio A Urbina \\ Instituto Venezolano de Investigaciones Científicas, Apartado 21827, 1020 Caracas, Venezuela
}

\begin{abstract}
This article presents an overview of the currently available drugs nifurtimox (NFX) and benznidazole (BZN) used against Trypanosoma cruzi, the aetiological agent of Chagas disease; herein we discuss their limitations along with potential alternatives with a focus on ergosterol biosynthesis inhibitors (EBI). These compounds are currently the most advanced candidates for new anti-T. cruzi agents given that they block de novo production of 24-alkylsterols, which are essential for parasite survival and cannot be replaced by a host's own cholesterol. Among these compounds, new triazole derivatives that inhibit the parasite's C14a sterol demethylase are the most promising, as they have been shown to have curative activity in murine models of acute and chronic Chagas disease and are active against NFX and BZN-resistant T. cruzi strains; among this class of compounds, posaconazole (Schering-Plough Research Institute) and ravuconazole (Eisai Company) are poised for clinical trials in Chagas disease patients in the short term. Other T. cruzi-specific EBI, with in vitro and in vivo potency, include squalene synthase, lanosterol synthase and squalene epoxidase-inhibitors as well as compounds with dual mechanisms of action (ergosterol biosynthesis inhibition and free radical generation), but they are less advanced in their development process. The main putative advantages of EBI over currently available therapies include their higher potency and selectivity in both acute and chronic infections, activity against NFX and BZN-resistant T. cruzi strains, and much better tolerability and safety profiles. Limitations may include complexity and cost of manufacture of the new compounds. As for any new drug, such compounds will require extensive clinical testing before being introduced for clinical use, and the complexity of such studies, particularly in chronic patients, will be compounded by the current limitations in the verification of true parasitological cures for T. cruzi infections.
\end{abstract}

Key words: chemotherapy - Trypanosoma cruzi - sterol biosynthesis - sterol C14 $\alpha$ demethylase - squalene synthase - oxidosqualene cyclise - amiodarone

Although a century has passed since the discovery of American Trypanosomiasis or Chagas disease (Chagas 1911), it remains the largest parasitic disease burden on the American continent, yet it is one of the most neglected parasitic diseases in the world; to combat the disease requires an integrated approach that addresses its underlying eco-socio-economic causes (Morel et al. 2005, Dias 2007, Holveck et al. 2007, Hotez et al. 2008). Significant advances have taken place to control the vectorial and transfusional transmission of the disease in some parts of the continent. In particular, the Southern Cone initiative has successfully interrupted reservoirto-human and human-to-human propagation of the disease in Uruguay, Chile and Brazil in recent years and has led to a marked reduction of the overall prevalence and the population at risk (Dias et al. 2002, Schofield et al. 2006). However, many challenges remain before full control or elimination of the disease can be achieved among them, inequality of the control programs in the various endemic areas (Attaran 2006, Schofield et al. 2006, Aguilar et al. 2007, Guhl 2007), limitations of cur-

Corresponding author: jurbina@mac.com

Received 19 March 2009

Accepted 18 May 2009 rently available specific chemotherapy, and insufficient treatment coverage for those currently infected with the aetiological agent, the parasitic protozoan Trypanosoma cruzi (Urbina \& Docampo 2003, Pinto Dias 2006, Jannin \& Villa 2007, Tarleton et al. 2007, Villa et al. 2007, Rassi et al. 2009).

Relevance of specific chemotherapy for Chagas disease and limitations of currently available drugs

Although the role of $T$. cruzi in the pathology and treatment of the acute phase of Chagas disease is widely accepted (Brener \& Gazzinelli 1997, Bahia-Oliveira et al. 2000, Kirchhoff et al. 2004), the parasite's influence on the pathogenesis of chronic Chagas disease has been the subject of controversies for decades (Cunha-Neto et al. 1995, Kalil \& Cunha-Neto 1996, Tarleton \& Zhang 1999, Tarleton 2001, 2003).

A key component of Chagas disease pathology is a sustained and diffuse inflammation of the affected organs with associated cytolysis and fibrosis, and the recognition of this phenomenon has led to intense studies to elucidate the origin and maintenance of such inflammatory responses. Several studies have implicated autoimmunity as a primary factor leading to the persistent inflammation associated with chronic Chagas disease pathology including chronic Chagas' cardiomyopathy (Cunha-Neto et al. 1995, Kalil \& Cunha-Neto 1996). This hypothesis was based on the apparent absence of the parasite in the characteristic inflammatory lesions 
of the heart and gastrointestinal tract coupled with the presence of "anti-self" antibody responses in Chagas disease patients; the latter is postulated to result from molecular mimicry between parasite antigens and a host's cellular components (Cunha-Neto et al. 1995, Kalil \& Cunha-Neto 1996). According to such a hypothesis, after the parasite triggers the autoimmune response in the host, its persistence does not play a pivotal role in the pathogenesis of the disease, and even successful antiparasitic treatment may not lead to an improvement in the clinical outcome of the patients. In fact, the autoimmune hypothesis of chronic Chagas disease pathogenesis, which temporally followed Köberle's neurogenic postulate, stalled for decades the development of new specific chemotherapeutic approaches for this disease, as antiparasitic treatment was considered irrelevant in both aforementioned hypotheses (Urbina 1999b, Urbina \& Docampo 2003).

However, more recent studies using more sensitive methodologies have shown clear correlations between the presence of the parasite and the inflammatory processes that underlie the pathological processes associated with chronic Chagas disease (Tarleton et al. 1997, Tarleton \& Zhang 1999, Tarleton 2001, 2003, Marin-Neto et al. 2007). This fact, coupled with the finding that $T$. cruzi-specific CD8+ and CD4+ T cells, are consistently associated with inflammatory infiltrates rich in Th1 cytokines, has led to the notion that parasite persistence is a necessary and sufficient condition to generate and sustain a Th1-biased inflammatory response in infected tissues, which may include autoimmune phenomena (Tarleton et al. 1997, Tarleton \& Zhang 1999, Tarleton 2001, 2003, Marin-Neto et al. 2007).

Thus, there is a growing consensus that the persistence of parasites, along with unbalanced immune responses in some individuals, leads to a sustained inflammatory response that underlies the characteristic lesions of chronic Chagas disease. This new paradigm suggests, in contrast to long-held views, that eradication of T. cruzi may be a prerequisite to arrest the evolution of Chagas disease and avert its irreversible long-term consequences, and it implies that this condition must be treated primarily as an infectious, not autoimmune, condition (Tarleton 2001, Urbina \& Docampo 2003, MarinNeto et al. 2007, Tarleton et al. 2007, Rassi et al. 2009).

Current specific chemotherapy for Chagas disease relies on two compounds empirically introduced for clinical use in the late 1960's and early 1970's: nifurtimox (NFX) [Lampit ${ }^{\circledR}$, Bayer; 5-nitrofuran 3-methyl-4-(5'nitrofurfurylideneamine) tetrahydro-4H-1,4-tiazine-1,1dioxide] and benznidazole (BZN) (Rochagan ${ }^{\circledR}$, Radanil $^{\circledR}$, Roche; N-benzyl-2-nitroimidazole acetamide) (Coura \& de Castro 2002, Pinto Dias 2006).

Numerous clinical studies, admittedly of unequal quality and duration, have shown that both drugs have significant activity during the acute phase (up to $80 \%$ negativisation of all parasitological and conventional serological tests) (Cançado 1999, 2002). However, their efficacies vary according to geographical area, most likely due to differences in drug susceptibility among different
T. cruzi strains (Filardi \& Brener 1987, Murta et al. 1998, Kirchhoff 1999). Moreover, it has been reported in the last 15 years that BZN also exhibits significant curative activity in those with recent onset (up to a few years) of chronic disease; $60-70 \%$ of radical parasitological cures have been observed among children up to 14 years of age in Brazil and Argentina (de Andrade et al. 1996, Andrade \& Zicker 1997, Sosa Estani et al. 1998, Sosa Estani \& Segura 1999, Andrade et al. 2004). On the other hand, other studies in patients of the same age range treated with either BZN or NFX contradict these conclusions (Silveira et al. 2000, Solari et al. 2001).

The major limitation of these compounds is insufficient antiparasitic activity in the chronic form of the disease, i.e., $\geq 80 \%$ of treated patients are not parasitologically cured according to the classical criteria indicated above for acute infections (Cançado 2002). These results have now been confirmed using PCR-based methods in both humans and experimental animals (Anez et al. 1999, Braga et al. 2000, Lauria-Pires et al. 2000, Britto et al. 2001, Garcia et al. 2005, Martins et al. 2008, Fernandes et al. 2009). The reasons for the marked difference in the antiparasitic efficacy of nitro-heterocyclic compounds in the acute and chronic stages of the disease are unclear (Cançado 2002), but they may be related to unfavourable pharmacokinetic properties, such as relatively short half-lives and limited tissue penetration (Raaflaub \& Ziegler 1979, Raaflaub 1980, Workman et al. 1984), which will limit their action in the chronic stage when the parasites are mostly confined in deep tissues and undergo slow replication (Urbina 1999a, Urbina \& Docampo 2003). In any case, verifying a true parasitological cure in chronic infection, where the levels of circulating parasites can be extremely low or undetectable even with the most sensitive PCR methods available (Martins et al. 2008), remains an extremely challenging problem that requires developing other criteria, such as immunological assays that measure T-cell responses to drug treatment (Bustamante et al. 2008).

Nevertheless, several observational clinical studies have shown that chronic patients subjected to antiparasitic treatment with BZN, although not parasitologically cured, achieve a significant reduction in the occurrence of electrocardiographic changes and a lower frequency of deterioration of their clinical condition (Viotti et al. 1994, 2006, Fragata Filho et al. 1995, Bahia-Oliveira et al. 2000, Fabbro De Suasnabar et al. 2000, Sosa-Estani \& Segura 2006, Viotti \& Vigliano 2007); however, other studies do not confirm these findings (Lauria-Pires et al. 2000, Sosa-Estani \& Segura 2006). The positive effect of current specific treatments, despite their inability to eradicate the parasite, on clinical evolution has been explained in terms of the parasite persistence hypothesis. That is, a drug-induced reduction of the parasite load in infected tissues reduces the severity of the associated inflammatory processes (Tarleton 2001, Viotti et al. 2006, Tarleton et al. 2007, Viotti \& Vigliano 2007).

Unfortunately, both drugs have unwanted side effects that can lead to treatment discontinuation (Coura $\&$ de Castro 2002, Rassi et al. 2009). The incidence of 
such side effects is variable and apparently depends on age, geographic region and the quality of the clinical supervision of the treatment (Coura \& de Castro 2002). Moreover, both NFX and BZN are genotoxic, as expected form their chemical nature and reactivity.

Due to the empirical nature of the discovery and development of NFX and BZN, these drugs were registered and used in clinical settings for many years without a clear understanding of their mechanism of action. By the mid-1980's, basic studies began to illuminate the molecular basis of both their anti-T. cruzi activity and toxicity (Docampo \& Moreno 1986, Docampo 1990). It has been experimentally demonstrated that the antiparasitic action of NFX is associated with the production of large amounts of toxic reactive oxygen species (ROS, such as superoxide anion and hydrogen peroxide), resulting from the reaction of oxygen with unstable nitroanion metabolites (Docampo \& Moreno 1986). However, BZN cytotoxicity is not associated with the generation of significant levels of ROS; instead, it probably results from reductive stress, which involves covalent modification of macromolecules by nitroreduction intermediates (Docampo \& Moreno 1986, Docampo 1990). Given the significant limitations of the currently available drugs, particularly for the treatment of chronic disease, new approaches to specific chemotherapy of Chagas disease have been advanced in the last two decades, and these will be discussed in the following sections with a focus on those candidates with the greatest probability of entering clinical studies in the short to medium-term.

\section{Ergosterol biosynthesis inhibitors (EBI) as potential new therapeutic agents for Chagas disease}

C14a-lanosterol demethylase (CYP51) inhibitors Research during the last two decades has consistently demonstrated that $T$. cruzi, like most fungi and yeasts, requires specific sterols for cell viability and proliferation in all stages of its life cycle. In particular, the ergosterol biosynthesis pathway has been chemically validated in vitro at many different steps (Urbina 2002, Urbina \& Docampo 2003). Yet, several studies have shown that commercially available EBI, which are highly successful for the treatment of fungal diseases (such as ketoconazole, itraconazole or terbinafine), have suppressive but not curative effects against $T$. cruzi infections in humans or experimental animals and are unable stop the progression of the disease (Urbina 2002, Urbina \& Docampo 2003). However, over the past 15 years, new triazole derivatives, e.g., D0870 (Zeneca Pharmaceuticals) and posaconazole (POS; SCH 56592; Schering-Plough Research Institute, SPRI) (Fig. 1), which are potent and selective inhibitors of fungal and protozoan cytochrome P-450-dependent CYP51, have been found to induce radical parasitological cure in murine models of acute and chronic Chagas disease (Urbina et al. 1996, Urbina 2002, Urbina \& Docampo 2003). These were the first compounds reported to display curative activity in both forms of the disease. Furthermore, such compounds were able to eradicate nitrofuran and nitroimidazoleresistant $T$. cruzi strains from infected mice, even if the
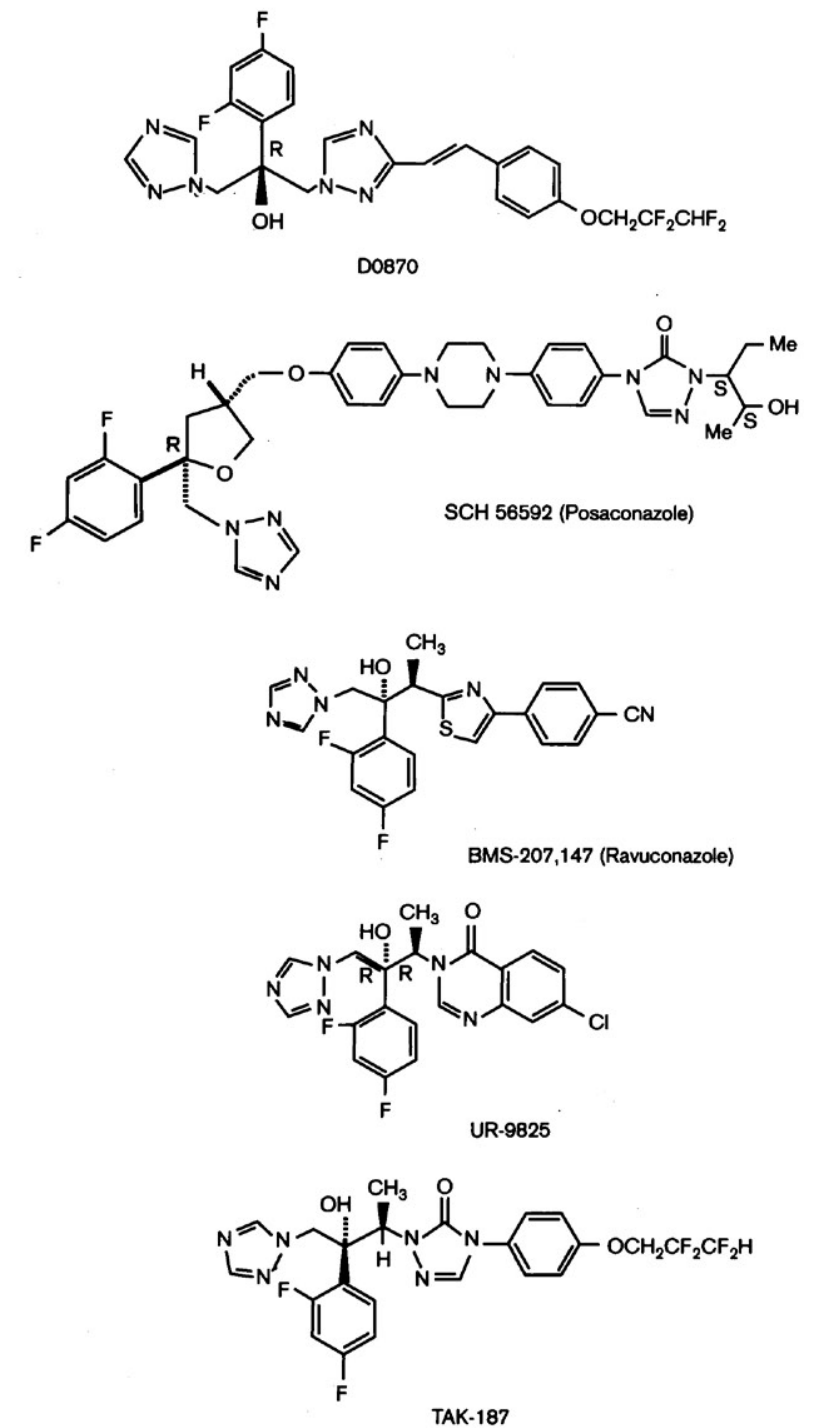

Fig. 1: chemical structures of novel triazole derivatives, specific inhibitors of fungal and protozoal sterol C14 $\alpha$-demethylase (CYP51), with curative activity in animal models of acute and chronic Chagas disease.

hosts were immunosuppressed (Urbina 2002, Urbina \& Docampo 2003). It has been argued that the remarkable in vivo antiparasitic activities of these triazole derivatives result from a combination of their potent and selective intrinsic anti-T. cruzi activity (the minimal growth inhibitory concentrations against the intracellular amastigote form is in the nanomolar to sub-nanomolar range) and special pharmacokinetic properties (long terminal half-life and large volumes of distribution) (Urbina 1999a, 2002, Urbina \& Docampo 2003).

More recent studies with POS, a structural analogue of itraconazole, have shown that this compound can eradicate the intracellular amastigote forms from cultured cardiomyocytes while allowing the full reassembly of the host cell's cytoskeleton and contractile apparatus (Silva et al. 2006). Other studies have demonstrated that the anti-T. cruzi activity of POS in a murine 
model of acute Chagas disease is much less dependent on interferon- $\gamma$ than that of BZN (Ferraz et al. 2007). It has also been shown that ablation of TCD4 ${ }^{+}, \mathrm{TCD}^{+}$ and B lymphocytes has distinct effects on POS and BZN activity in the same experimental model (Ferraz et al. 2009). POS efficacy was especially dependent on the presence of functional TCD $8^{+}$cells, but relatively insensitive to the absence of LB cells, yet the reverse was true for BZN; the activity of both drugs was markedly reduced in the absence of TCD4 $4^{+}$cells. These results were interpreted in terms of the different parasite stages preferentially targeted by the two drugs (intracellular amastigotes by POS, extracellular trypomastigotes by BZN) and distinct cooperation patterns with the host's immune system (Ferraz et al. 2009). An independent study in a similar experimental model found that POS was more effective than BZN in preventing heart damage and promoting a trypanocidal immune response (Olivieri et al., unpublished observations). POS was registered in 2005 in the European Union and Australia for treatment and, in 2006, in the USA for the prophylaxis of invasive fungal infections and for the treatment azole-resistant candidiasis. It is poised to enter clinical development for the treatment of human chronic Chagas disease in the next 12 months. This will be the first rationally designed drug to enter clinical trials for the treatment of this disease.

Other triazoles (Fig. 1), such as TAK-187 (Takeda Chemical Company) (Urbina et al. 2003c, Corrales et al. 2005), UR-9825 (Uriach \& Company) (Urbina et al. 2000, Guedes et al. 2004) and ravuconazole (ER-30346, Eisai Co.; BMS 207,147; Bristol-Myers Squibb) (Urbina et al. 2003b) also exhibit trypanocidal activity in vitro and in vivo. TAK-187 is a long-lasting triazole derivative with broad-spectrum antifungal activity, which also possesses very potent anti-T. cruzi activity in vitro and is capable of curing both acute and chronic infections in murine hosts even when the infecting strain is resistant to nitrofuran and nitroimidazole (Urbina et al. 2003c). More recent work has shown that this compound is superior to BZN in preventing cardiac damage in a murine Chagas disease model (Corrales et al. 2005). UR-9825 is another potent fungal and protozoan CYP51 inhibitor with remarkable in vitro anti-T. cruzi activity (Urbina et al. 2000). However, its very short half-life in the mouse $(<0.5 \mathrm{~h})$ precluded in vivo studies in this animal model, but work in a canine model has demonstrated that the compound exhibits curative activity against established infections of the virulent $\mathrm{Y}$ strain of T. cruzi with very low toxicity, although drug resistance was encountered with the Berenice-78 strain (Guedes et al. 2004). Finally, ravuconazole has also been shown to be very active against $T$. cruzi in vitro, but its in vivo activity in mice was limited, most likely due to inadequate pharmacokinetic properties in this animal model (terminal half-life of $4.5 \mathrm{~h}$ ) (Urbina et al. 2003b). Similarly, the activity of ravuconazole in a canine model of acute Chagas disease was found to be suppressive, not curative, a result that was again attributed to the relatively short half-life of the compound in dogs $(8.8 \mathrm{~h}$ ) (MT Bahia \& JA Urbina, unpublished observations). However, these results do not necessarily rule out the potential usefulness of this compound in the treatment of human T. cruzi infections since its minimal inhibitory concentration against intracellular amastigotes $(1 \mathrm{nM})$ is $1,000-5,000$-fold lower than the levels attainable in human plasma following multiple oral dosages, and its terminal half-life in man is $\geq 120 \mathrm{~h}$ (Mikamo et al. 2002, Andes et al. 2003). This compound is another prime candidate for clinical trials regarding Chagas disease patients.

Another class of azole-based CYP51 inhibitors that possess potent anti-T. cruzi activity in vitro and in vivo was serendipitously discovered in the course of a research program to identify parasite-specific protein farnesylation inhibitors and represents an interesting alternative to the proprietary compounds described above (Buckner et al. 2003, Hucke et al. 2005, Buckner 2008, Kraus et al. 2009). Very recently, a new class of T. cruzi CYP51 inhibitors, based on the N-[4-pyridyl]-formamide moiety and derived from a Mycobacterium tuberculosis screen hit, has been described (Chen et al. 2009); one of the new compounds was able to eradicate intracellular amastigotes grown in cultured mouse macrophages.

Squalene synthase (SQS) inhibitors - A different group of promising T. cruzi agents among EBIs is that of SQS inhibitors. SQS catalyses the first committed step in sterol biosynthesis and has been the subject of intense study by both academic and industrial groups as an attractive target for cholesterol lowering agents. It presents potentially significant advantages over currently available statins (Tansey \& Shechter 2001, Menys \& Durrington 2003, Suckling 2006, Charlton-Menys $\&$ Durrington 2007). This enzyme has been recently chemically validated as a chemotherapeutic target in T. cruzi and Leishmania mexicana (Urbina et al. 2002). Further studies led to the discovery that E5700 and ER-119884, two novel quinuclidine SQS inhibitors currently under development as cholesterol and triglyceride lowering agents in humans by Eisai Company (Fig. 2), have very potent anti-T. cruzi activity in vitro. One of them (E5700) was able to provide full protection against death, and it completely arrested development of parasitaemia in a murine model of acute disease when given orally (Urbina et al. 2004), this was the first report of an orally-active SQS inhibitor as an anti-infective agent. Although these compounds and other aryl-quinuclidines are also potent inhibitors of mammalian SQS (McTaggart et al. 1996, Ward et al. 1996, Ishihara et al. 2003, 2004), their selective antiparasitic activity in vitro and in vivo might be explained by the capacity of a host's cells to compensate for the blockade of de novo cholesterol synthesis by up-regulating the expression of LDL receptors and capturing this sterol from the growth medium or serum (Goldstein \& Brown 2001). In contrast, there is no way for the parasite to compensate in this manner for the quinuclidine-induced blockade of ergosterol biosynthesis since there are no appreciable amounts of ergosterol in host cells or growth media (Urbina et al. 2002 , 2004). However, the requirement of some key organs (such as testis) of an elevated "endogenous" cholesterol supply could pose a significant limitation for the prolonged use of these SQS inhibitors. In fact, prolonged 
use of selective SQS inhibitors (and statins) has been associated with testicular atrophy in experimental animals (Eisai Co, data on file). Thus, the use of this class of compounds as antiparasitic agents will probably require parasite-specific SQS inhibitors in much the same way that current antifungal azoles are specific for fungal and parasite CYP51 while having much less of an effect on the enzyme's mammalian orthologue. Recent work has demonstrated progress towards this goal, as the gene encoding T. cruzi SQS has been cloned and expressed in Escheria coli, resulting in the production of a soluble, fully active, recombinant enzyme, which has been used to identify parasite-specific SQS inhibitors (Orenes Lorente et al. 2005, Sealey-Cardona et al. 2007). Finally, it has also been shown that aryloxylethyl thiocyanates such as WC-9 (4-phenoxyphenoxyethylthiocyanate), a new class of potent and selective anti-T. cruzi agents (Szajnman et al. 2000, Elhalem et al. 2002), act by selectively inhibiting the parasite's SQS (Urbina et al. 2003a).

Lanosterol synthase [oxidosqualene cyclise (OSC)] inhibitors - Another advance in the area of EBIs as antiparasitic agents is the validation of OSC as a chemotherapeutic target in $T$. cruzi and related parasites (Buckner et al. 2000, 2001, Joubert et al. 2001). Buckner et al. demonstrated the potent and selective in vitro antiparasitic activities of OSC inhibitors (Buckner et al. 2001, Hinshaw et al. 2003) and a patent submitted by the same authors claims the use of OSC inhibitors as chemotherapeutic agents for the specific treatment of parasitic infections, including Chagas disease [US Patent WO0076316 (Urbina 2003)]. However, no in vivo activity of this class of compounds has been reported. A related development was the surprising discovery that amiodarone, a bis-aryl-ketone (Fig. 3) used extensively as an antiarrhythmic drug in chronic Chagas disease patients with cardiac compromise (Rosenbaum et al. 1983, Rassi et al. 2000, 2009), has intrinsic anti-T. cruzi activity in vitro and in vivo and that combinations of this drug with posaconazole have synergistic effects (Benaim et al. 2006). It was found that amiodarone functions via dual mechanisms of action against this parasite: disruption of $\mathrm{Ca}^{2+}$ homeostasis and blockade of de novo ergosterol biosynthesis at the level of OSC, which explains the synergistic effects observed with posaconazole. The results indicate that Chagas disease patients being treated with amiodarone may have the added benefit of a reduction of their parasite burden and enhancement of the effects of antiparasitic treatment (Benaim et al. 2006).

Hybrid compounds with dual mechanisms of action An interesting development in this area is a recent report on the synthesis and chemical/biological characterisation of compounds with dual mechanisms of action resulting from the presence of two pharmacophores in the same molecule: a nitrofuran moiety that leads to free radical generation and redox cycling and a heteroallyl moiety that inhibits squalene epoxidase, a key enzyme in sterol biosynthesis (Gerpe et al. 2008). These heteroallylcontaining 5-nitrofuran compounds were very active against both the extracellular and intracellular forms of the parasite in vitro and more potent than NFX and terbi-

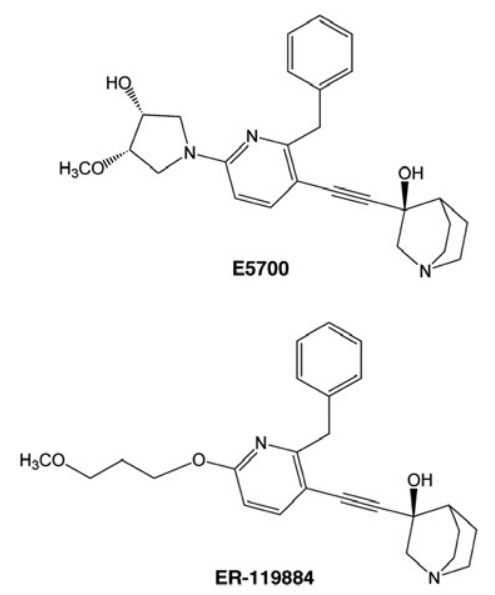

Fig. 2: chemical structures of novel aryl-quinuclidine derivatives with potent in vitro and in vivo (oral) activity against Trypanosoma cruzi.

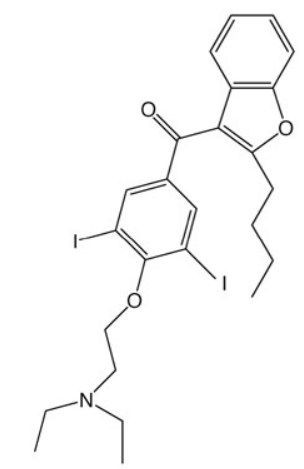

Fig. 3: chemical structure of amiodarone, the antiarrhythmic drug most frequently used in chronic Chagas disease patients with cardiac compromise, which also has intrinsic anti-Trypanosoma cruzi activity in vitro and in vivo.

nafine, a commercial squalene epoxidase inhibitor with antifungal activity. The potential of this new class of compounds is underscored by previous studies (Araujo et al. 2000) that showed that combination therapy with BZN and the EBI ketoconazole had synergistic effects in a murine model of acute Chagas disease.

In conclusion, EBI are currently the most advanced candidates for new specific treatments for Chagas disease, as some of them could enter clinical trials in the short-term (within 24 months). Their primary advantages over currently available therapies include their higher potency in both acute and chronic infections, activity against NFX and BZN-resistant T. cruzi strains, and their enhanced tolerability and safety profiles resulting from their selective mechanisms of action. Limitations may include complexity and cost of manufacturing the new compounds and the uneven advancement of various candidates in the drug development process, but there are several options in the pipeline that can address such issues. As for any new drug, such compounds will require 
extensive clinical testing before being introduced for clinical use. The complexity of these studies, particularly in chronic patients, will be compounded by the current limitations in the verification of true parasitological cures for $T$. cruzi infections. Despite these shortcomings, this class of compounds remains the best hope for millions of patients currently living with this insidious, silent killer.

\section{REFERENCES}

Aguilar HM, Abad-Franch F, Dias JC, Junqueira AC, Coura JR 2007. Chagas disease in the Amazon region. Mem Inst Oswaldo Cruz 102: $47-56$.

Andes D, Marchillo K, Stamstad T, Conklin R 2003. In vivo pharmacodynamics of a new triazole, ravuconazole, in a murine candidiasis model. Antimicrob Agents Chemother 47: 1193-1199.

Andrade AL, Martelli CM, Oliveira RM, Silva SA, Aires AI, Soussumi LM, Covas DT, Silva LS, Andrade JG, Travassos LR, Almeida IC 2004. Short report: benznidazole efficacy among Trypanosoma cruzi-infected adolescents after a six-year follow-up. Am J Trop Med Hyg 71: 594-597.

Andrade ALS, Zicker F 1997. Should benznidazole be used in chronic Chagas' disease? Lancet 349: 653-660.

Anez N, Carrasco H, Parada H, Crisante G, Rojas A, Fuenmayor C, Gonzalez N, Percoco G, Borges R, Guevara P, Ramirez JL 1999. Myocardial parasite persistence in chronic chagasic patients. $\mathrm{Am}$ J Trop Med Hyg 60: 726-732.

Araujo MS, Martins-Filho OA, Pereira ME, Brener Z 2000. A combination of benznidazole and ketoconazole enhances efficacy of chemotherapy of experimental Chagas' disease. J Antimicrob Chemother 45: 819-824.

Attaran A 2006. Chagas' disease in Mexico. Lancet 368: 1768; discussion 1768-1769.

Bahia-Oliveira LM, Gomes JA, Cançado JR, Ferrari TC, Lemos EM, Luz ZM, Moreira MC, Gazzinelli G, Correa-Oliveira R 2000. Immunological and clinical evaluation of chagasic patients subjected to chemotherapy during the acute phase of Trypanosoma cruzi infection 14-30 years ago. J Infect Dis 182: 634-638.

Benaim, G, Sanders JM, Garcia-Marchan Y, Colina C, Lira R, Caldera AR, Payares G, Sanoja C, Burgos JM, Leon-Rossell A, Concepcion JL, Schijman AG, Levin M, Oldfield E, Urbina JA 2006. Amiodarone has intrinsic anti-Trypanosoma cruzi activity and acts synergistically with Posaconazole. J Med Chem 49: 892-899.

Braga MS, Lauria-Pires L, Arganaraz ER, Nascimento RJ, Teixeira A R 2000. Persistent infections in chronic Chagas' disease patients treated with anti-Trypanosoma cruzi nitroderivatives. Rev Inst Med Trop Sao Paulo 42: 157-161.

Brener Z, Gazzinelli RT 1997. Immunological control of Trypanosoma cruzi infection and pathogenesis of Chagas' disease. Int Arch Allergy Immunol 114: 103-110.

Britto C, Silveira C, Cardoso MA, Marques P, Luquetti A, Macedo V, Fernandes O 2001. Parasite persistence in treated chagasic patients revealed by xenodiagnosis and polymerase chain reaction. Mem Inst Oswaldo Cruz 96: 823-826.

Buckner F, Yokoyama K, Lockman J, Aikenhead K, Ohkanda J, Sadilek M, Sebti S, Van Voorhis W, Hamilton A, Gelb MH 2003. A class of sterol 14-demethylase inhibitors as anti-Trypanosoma cruzi agents. Proc Natl Acad Sci USA 100: 15149-15153.

Buckner FS 2008. Sterol 14-demethylase inhibitors for Trypanosoma cruzi infections. Adv Exp Med Biol 625: 61-80.
Buckner FS, Griffin JH, Wilson AJ, Van Voorhis WC 2001. Potent anti-Trypanosoma cruzi activities of oxidosqualene cyclase inhibitors. Antimicrob Agents Chemother 45: 1210-1215.

Buckner FS, Nguyen LN, Joubert BM, Matsuda SP 2000. Cloning and expression of the Trypanosoma brucei lanosterol synthase gene. Mol Biochem Parasitol 110: 399-403.

Bustamante JM, Bixby LM, Tarleton RL 2008. Drug-induced cure drives conversion to a stable and protective CD $8(+)$ T central memory response in chronic Chagas disease. Nat Med 14: 542-550.

Cançado JR 1999. Criteria of Chagas disease cure. Mem Inst Oswaldo Cruz 94: 331-336.

Cançado JR 2002. Long term evaluation of etiological treatment of chagas disease with benznidazole. Rev Inst Med Trop Sao Paulo 44: 29-37.

Chagas C 1911. Nova entidade morbida do homen. Resumo geral dos estudos etiológicos e clínicos. Mem Inst Oswaldo Cruz 3: 219-275.

Charlton-Menys V, Durrington PN 2007. Squalene synthase inhibitors : clinical pharmacology and cholesterol-lowering potential. Drugs 67: 11-16.

Chen CK, Doyle PS, Yermalitskaya LV, Mackey ZB, Ang KK, McKerrow JH, Podust LM 2009. Trypanosoma cruzi CYP51 inhibitor derived from a Mycobacterium tuberculosis screen hit. PLoS Negl Trop Dis 3: e372.

Corrales M, Cardozo R, Segura MA, Urbina JÁ, Basombrio MA 2005. Comparative efficacies of TAK-187, a long-lasting ergosterol biosynthesis inhibitor, and benznidazole in preventing cardiac damage in a murine model of Chagas' disease. Antimicrob Agents Chemother 49: 1556-1560.

Coura JR, de Castro SL 2002. A critical review on Chagas disease chemotherapy. Mem Inst Oswaldo Cruz 97: 3-24.

Cunha-Neto E, Duranti M, Gruber A, Zingales B, De Messias I, Stolf N, Bellotti G, Patarroyo ME, Kalil J 1995. Autoinmunity in Chagas disease cardiopathy: Biological relevance of a cardiac myosinspecific epitope crossreactive to an inmunodominant Trypanosoma cruzi antigen. Proc Natl Acad Sci USA 92: 3541-3545.

de Andrade AL, Zicker F, de Oliveira RM, Almeida Silva S, Luquetti A, Travassos LR, Almeida IC, de Andrade SS, de Andrade JG, Martelli CM 1996. Randomised trial of efficacy of benznidazole in treatment of early Trypanosoma cruzi infection. Lancet 348: 1407-1413.

Dias JC 2007. Globalization, inequity and Chagas disease. Cad Saude Publica 23: S13-22.

Dias JC, Silveira AC, Schofield CJ 2002. The impact of Chagas disease control in Latin America: a review. Mem Inst Oswaldo Cruz 97: 603-612.

Docampo R 1990. Sensitivity of parasites to free radical damage by antiparasitic drugs. Chem Biol Interact 73: 1-27.

Docampo R, Moreno SN 1986. Free radical metabolism of antiparasitic agents. Fed Proc 45: 2471-2476.

Elhalem E, Bailey BN, Docampo R, Ujvary I, Szajnman SH, Rodriguez JB 2002. Design, synthesis, and biological evaluation of aryloxyethyl thiocyanate derivatives against Trypanosoma cruzi. J Med Chem 45: 3984-3999.

Fabbro De Suasnabar D, Arias E, Streiger M, Piacenza M, Ingaramo M, Del Barco M, Amicone N 2000. Evolutive behavior towards cardiomyopathy of treated (nifurtimox or benznidazole) and untreated chronic chagasic patients. Rev Inst Med Trop Sao Paulo 42: 99-109.

Fernandes CD, Tiecher FM, Balbinot MM, Liarte DB, Scholl D, Steindel M, Romanha A 2009. Efficacy of benznidazol treatment for asymptomatic chagasic patients from state of Rio Grande do 
Sul evaluated during a three years follow up. Mem Inst Oswaldo Cruz 104: 27-32.

Ferraz ML, Gazzinelli RT, Alves RO, Urbina JA, Romanha AJ 2007. The Anti-Trypanosoma cruzi activity of posaconazole in a murine model of acute Chagas' disease is less dependent on gamma interferon than that of benznidazole. Antimicrob Agents Chemother 51: 1359-1364.

Ferraz ML, Gazzinelli RT, Alves RO, Urbina JA, Romanha AJ 2009. Absence of CD4+ T lymphocytes, CD8+ T lymphocytes, or B lymphocytes has different effects on the efficacy of posaconazole and benznidazole in treatment of experimental acute Trypanosoma cruzi infection. Antimicrob Agents Chemother 53: 174-179.

Filardi LS, Brener Z 1987. Susceptibility and natural resistance of Trypanosoma cruzi strains to drugs used clinically in Chagas disease. Trans R Soc Trop Med Hyg 81: 755-759.

Fragata Filho AA, da Silva MA, Boainain E 1995. Ethiologic treatment of acute and chronic Chagas' Disease [corrected]. Sao Paulo Med J 113: 867-872.

Garcia S, Ramos CO, Senra J F, Vilas-Boas F, Rodrigues MM, Campos-de-Carvalho A C, Ribeiro-dos-Santos R, Soares MB 2005. Treatment with benznidazole during the chronic phase of experimental Chagas' disease decreases cardiac alterations. Antimicrob Agents Chemother 49: 1521-1528.

Gerpe A, Odreman-Nunez I, Draper P, Boiani L, Urbina J A, Gonzalez M, Cerecetto H 2008. Heteroallyl-containing 5-nitrofuranes as new anti-Trypanosoma cruzi agents with a dual mechanism of action. Bioorg Med Chem 16: 569-577.

Goldstein JL, Brown MS 2001. The Cholesterol Quartet. Science 292: 1310- 1312.

Guedes PM, Urbina JA, de Lana M, Afonso LC, Veloso VM, Tafuri WL, Machado-Coelho GL, Chiari E, Bahia MT 2004. Activity of the new triazole derivative albaconazole against Trypanosoma (Schizotrypanum) cruzi in dog hosts. Antimicrob Agents Chemother 48: 4286-4292.

Guhl F 2007. Chagas disease in Andean countries. Mem Inst Oswaldo Cruz 102: 29-38.

Hinshaw JC, Suh DY, Garnier P, Buckner FS, Eastman RT, Matsuda SP, Joubert BM, Coppens I, Joiner KA, Merali S, Nash TE, Prestwich GD 2003. Oxidosqualene cyclase inhibitors as antimicrobial agents. J Med Chem 46: 4240-4243.

Holveck JC, Ehrenberg JP, Ault SK, Rojas R, Vasquez J, Cerqueira MT, Ippolito-Shepherd J, Genovese MA, Periago MR 2007. Prevention, control, and elimination of neglected diseases in the Americas: pathways to integrated, inter-programmatic, inter-sectoral action for health and development. BMC Public Health 7: 6.

Hotez PJ, Bottazzi ME, Franco-Paredes C, Ault SK, Periago MR 2008. The neglected tropical diseases of latin america and the Caribbean: a review of disease burden and distribution and a roadmap for control and elimination. PLoS Negl Trop Dis 2: e300.

Hucke O, Gelb MH, Verlinde CL, Buckner FS 2005. The protein farnesyltransferase inhibitor Tipifarnib as a new lead for the development of drugs against Chagas disease. J Med Chem 48: 5415-5418.

Ishihara T, Kakuta H, Moritani H, Ugawa T, Sakamoto S, Tsukamoto S, Yanagisawa I 2003. Syntheses and biological evaluation of novel quinuclidine derivatives as squalene synthase inhibitors. Bioorg Med Chem 11: 2403-2414.

Ishihara T, Kakuta H, Moritani H, Ugawa T, Yanagisawa I 2004. Synthesis and biological evaluation of quinuclidine derivatives incorporating phenothiazine moieties as squalene synthase inhibitors. Chem Pharm Bull 52: 1204-1209.
Jannin J, Villa L 2007. An overview of Chagas disease treatment. Mem Inst Oswaldo Cruz 102: 95-97.

Joubert BM, Buckner FS, Matsuda SP 2001. Trypanosome and animal lanosterol synthases use different catalytic motifs. Org Lett 14: $1957-1960$

Kalil J, Cunha-Neto E 1996. Autoimmunity in Chagas disease cardiomyopathy: Fullfilling the criteria at last? Parasitol Today 12: 396-399.

Kirchhoff LV 1999. Chagas' disease (American Trypanosomiasis): a tropical disease now emerging in the United States. In WM Scheld, WA Craig, JM Hughes, Emerging Infections, ASM Press, Washington, p. 111-134.

Kirchhoff LV, Weiss LM, Wittner M, Tanowitz HB 2004. Parasitic diseases of the heart. Front Biosci 9: 706-723.

Kraus JM, Verlinde CL, Karimi M, Lepesheva GI, Gelb MH, Buckner FS 2009. Rational modification of a candidate cancer drug for use against Chagas disease. J Med Chem 52: 1639-1647.

Lauria-Pires L, Braga MS, Vexenat AC, Nitz N, Simoes-Barbosa A, Tinoco DL, Teixeira AR 2000. Progressive chronic Chagas heart disease ten years after treatment with anti-Trypanosoma cruzi nitroderivatives. Am J Trop Med Hyg 63: 111-118.

Marin-Neto JA, Cunha-Neto E, Maciel BC, Simoes MV 2007. Pathogenesis of chronic Chagas heart disease. Circulation 115: 1109-1123.

Martins HR, Figueiredo LM, Valamiel-Silva JC, Carneiro CM, Machado-Coelho GL, Vitelli-Avelar DM, Bahia MT, Martins-Filho OA, Macedo AM, Lana M 2008. Persistence of PCR-positive tissue in benznidazole-treated mice with negative blood parasitological and serological tests in dual infections with Trypanosoma cruzi stocks from different genotypes. J Antimicrob Chemother 61: 1319-1327.

McTaggart F, Brown GR, Davidson RG, Freeman S, Holdgate GA, Mallion KB, Mirrlees DJ, Smith GJ, Ward WHJ 1996. Inhibition of squalene synthase of rat liver by novel 3' substituted quinuclidines. Biochem Pharmacol 51: 1477-1487.

Menys VC, Durrington PN 2003. Squalene synthase inhibitors. Br J Pharmacol 139: 881-882.

Mikamo H, Yin XH, Hayasaki Y, Shimamura Y, Uesugi K, Fukayama N, Satoh M, Tamaya T 2002. Penetration of ravuconazole, a new triazole antifungal, into rat tissues. Chemotherapy 48: 7-9.

Morel CM, Acharya T, Broun D, Dangi A, Elias C, Ganguly NK, Gardner CA, Gupta RK, Haycock J, Heher AD, Hotez PJ, Kettler HE, Keusch GT, Krattiger AF, Kreutz FT, Lall S, Lee K, Mahoney R, Martinez-Palomo A, Mashelkar RA, Matlin SA, Mzimba M, Oehler J, Ridley RG, Senanayake P, Singer P, Yun M 2005. Health innovation networks to help developing countries address neglected diseases. Science 309: 401-404.

Murta SM, Gazzinelli RT, Brener Z, Romanha AJ 1998. Molecular characterization of susceptible and naturally resistant strains of Trypanosoma cruzi to benznidazole and nifurtimox. Mol Biochem Parasitol 93: 203-214.

Orenes Lorente S, Gomez R, Jimenez C, Cammerer S, Yardley V, de Luca-Fradley K, Croft SL, Ruiz Perez LM, Urbina J, Gonzalez Pacanowska D, Gilbert IH 2005. Biphenylquinuclidines as inhibitors of squalene synthase and growth of parasitic protozoa. Bioorg Med Chem 13: 3519-3529.

Pinto Dias JC 2006. The treatment of Chagas disease (South American trypanosomiasis). Ann Intern Med 144: 772-774.

Raaflaub J 1980. Multiple-dose kinetics of the trypanosomicide benznidazole in man. Arzneimittelforschung 30: 2192-2194.

Raaflaub J, Ziegler WH 1979. Single-dose pharmacokinetics of the trypanosomicide benznidazole in man. Arzneimittelforschung 29: 1611-1614. 
Rassi A Jr, Dias JC, Marin-Neto JA, Rassi A 2009. Challenges and opportunities for primary, secondary, and tertiary prevention of Chagas disease. Heart 95: 524-534

Rassi A Jr, Rassi A, Little WC 2000. Chagas' heart disease. Clin Cardiol 23: 883-889.

Rosenbaum MB, Chiale PA, Haedo A, Lazzari JO, Elizari MV 1983. Ten years of experience with amiodarone. Am Heart J 106: 957-964.

Schofield CJ, Jannin J, Salvatella R 2006. The future of Chagas disease control. Trends Parasitol 22: 583-588.

Sealey-Cardona M, Cammerer S, Jones S, Ruiz-Perez LM, Brun R, Gilbert IH, Urbina JA, Gonzalez-Pacanowska D 2007. Kinetic characterization of squalene synthase from Trypanosoma cruzi: selective inhibition by quinuclidine derivatives. Antimicrob Agents Chemother 51: 2123-2129.

Silva DT, de Meirelles MN, Almeida D, Urbina JA, Pereira MC 2006. Cytoskeleton reassembly in cardiomyocytes infected by Trypanosoma cruzi is triggered by treatment with ergosterol biosynthesis inhibitors. Int J Antimicrob Agents 27: 530-537.

Silveira CA, Castillo E, Castro C 2000. Evaluation of an specific treatment for Trypanosoma cruzi in children, in the evolution of the indeterminate phase. Rev Soc Bras Med Trop 33: 191-196.

Solari A, Ortiz S, Soto A, Arancibia C, Campillay R, Contreras M, Salinas P, Rojas A, Schenone H 2001. Treatment of Trypanosoma cruzi-infected children with nifurtimox: a 3 year follow-up by PCR. J Antimicrob Chemother 48: 515-519.

Sosa Estani S, Segura EL 1999. Treatment of Trypanosoma cruzi infection in the undetermined phase. Experience and current guidelines of treatment in Argentina. Mem Inst Oswaldo Cruz 94: 363-365.

Sosa Estani S, Segura EL, Ruiz AM, Velazquez E, Porcel BM, Yampotis C 1998. Efficacy of chemotherapy with benznidazole in children in the indeterminate phase of Chagas' disease. $\mathrm{Am} J$ Trop Med Hyg 59: 526-529.

Sosa-Estani S and Segura EL 2006. Etiological treatment in patients infected by Trypanosoma cruzi: experiences in Argentina. Curr Opin Infect Dis 19: 583-587.

Suckling KE 2006. The return of two old targets? Expert Opin Ther Targets 10: 785-788.

Szajnman SH, Yan W, Bailey BN, Docampo R, Elhalem E, Rodriguez JB 2000. Design and synthesis of aryloxyethyl thiocyanate derivatives as potent inhibitors of Trypanosoma cruzi proliferation. $J$ Med Chem 43: 1826-1840.

Tansey TR, Shechter I 2001. Squalene synthase: structure and regulation. Prog Nucleic Acid Res Mol Biol 65: 157-195.

Tarleton RL 2001. Parasite persistence in the aetiology of Chagas disease. Int J Parasitol 31: 550-554.

Tarleton RL 2003. Chagas disease: a role for autoimmunity? Trends Parasitol 19: 447-451.

Tarleton RL, Reithinger R, Urbina JA, Kitron U, Gurtler RE 2007. The challenges of Chagas disease - grim outlook or glimmer of hope. PLoS Med 4: e332.

Tarleton RL, Zhang L 1999. Chagas disease etiology: autoimmunity or parasite persistence? Parasitol Today 15: 94-99.

Tarleton RL, Zhang L, Downs MO 1997. "Autoimmune rejection" of neonatal heart transplants in experimental Chagas disease is a parasite-specific response to infected host tissue. Proc Natl Acad Sci USA 94: 3932-3937.

Urbina JA 1999a. Chemotherapy of Chagas' Disease: The how and the why. J Mol Med 77: 332-338.
Urbina JA 1999b. Parasitological cure of Chagas disease: Is it possible? Is it relevant? Mem Inst Oswaldo Cruz 94: 349-355.

Urbina JA 2002. Chemotherapy of Chagas Disease. Curr Pharm Design 8: 287-295.

Urbina JA 2003. New chemotherapeutic approaches for the treatment of Chagas disease (American Trypanosomiasis). Expert Op Ther Pat 13: 661-669.

Urbina JA, Concepcion JL, Caldera A, Payares G, Sanoja C, Otomo T, Hiyoshi H 2004. In vitro and in vivo activities of E5700 and ER-119884, two novel orally active squalene synthase inhibitors, against Trypanosoma cruzi. Antimicrob Agents Chemother 48: 2379-2387.

Urbina JA, Concepcion JL, Montalvetti A, Rodriguez JB, Docampo R 2003a. Mechanism of action of 4-phenoxyphenoxyethyl thiocyanate (WC-9) against Trypanosoma cruzi, the causative agent of Chagas' disease. Antimicrob Agents Chemother 47: 2047-2050.

Urbina JA, Concepcion JL, Rangel S, Visbal G, Lira R 2002. Squalene synthase as a chemotherapeutic target in Trypanosoma cruzi and Leismania mexicana. Mol Biochem Parasitol 125: 35-45.

Urbina JA, Docampo R 2003. Specific chemotherapy of Chagas disease: controversies and advances. Trends Parasitol 19: 495-501.

Urbina JA, Lira R, Visbal G, Bartrolí J 2000. In vitro antiproliferative effects and mechanism of action of the new triazole derivative UR-9825 against the protozoan parasite Trypanosoma (Schizotrypanum) cruzi. Antimicrob. Agents Chemother 44: 2498-2502.

Urbina JA, Payares G, Molina J, Sanoja C, Liendo A, Lazardi K, Piras MM, Piras R, Perez N, Wincker P, Ryley JF 1996. Cure of short- and long-term experimental Chagas' disease using D0870. Science 273: 969-971.

Urbina JA, Payares G, Sanoja C, Lira R and Romanha AJ 2003b. In vitro and in vivo activities of ravuconazole on Trypanosoma cruzi, the causative agent of Chagas disease. Intern J Antimicrob Agents 21: 27-38.

Urbina JA, Payares G, Sanoja C, Molina J, Lira R, Brener Z, Romanha AJ 2003c. Parasitological cure of acute and chronic experimental Chagas disease using the long-acting experimental triazole TAK187. Activity against drug resistant Trypanosoma cruzi strains. Int J Antimicrob Agents 21: 39-48.

Villa L, Morote S, Bernal O, Bulla D, Albajar-Vinas P 2007. Access to diagnosis and treatment of Chagas disease/infection in endemic and non-endemic countries in the XXI century. Mem Inst Oswaldo Cruz 102: 87-94.

Viotti R, Vigliano C 2007. Etiological treatment of chronic Chagas disease: neglected 'evidence' by evidence-based medicine. Expert Rev Anti Infect Ther 5: 717-726.

Viotti R, Vigliano C, Armenti H, Segura E 1994. Treatment of chronic Chagas' disease with benznidazole: Clinical and serologic evolution of patients with longterm follow-up. Am Heart J 127: 151-162.

Viotti R, Vigliano C, Lococo B, Bertocchi G, Petti M, Alvarez MG, Postan M, Armenti A 2006. Long-term cardiac outcomes of treating chronic Chagas disease with benznidazole versus no treatment: a nonrandomized trial. Ann Intern Med 144: 724-34.

Ward WHJ, Holdgate GA, Freeman S, McTaggart F, Girdwood PA, Davidson RG, Mallion KB, Brown GR, Eakin MA 1996. Inhibition of squalene synthase in vitro by 3-(biphenyl-4-yl)-quinuclidine. Biochem Pharmacol 51: 1489-1501.

Workman P, White RA, Walton MI, Owen LN, Twentyman PR 1984. Preclinical pharmacokinetics of benznidazole. Br J Cancer 50: 291-303. 